Purdue University

Purdue e-Pubs

Time-Resolved Characterization of Microchannel Flow Boiling

During Transient Heating: Part 2 - Dynamic Response to Time-

Periodic Heat Flux Pulses

\author{
T. A. Kingston
}

J. A. Weibel

S V. Garimella

Follow this and additional works at: https://docs.lib.purdue.edu/coolingpubs

This document has been made available through Purdue e-Pubs, a service of the Purdue University Libraries.

Please contact epubs@purdue.edu for additional information. 


\title{
Time-Resolved Characterization of Microchannel Flow Boiling During Transient Heating: Part 2 - Dynamic Response to Time- Periodic Heat Flux Pulses ${ }^{1}$
}

\author{
Todd A. Kingston ${ }^{2}$, Justin A. Weibel*, and Suresh V. Garimella ${ }^{3 *}$ \\ Cooling Technologies Research Center \\ School of Mechanical Engineering, Purdue University, West Lafayette, Indiana 47907 USA
}

\begin{abstract}
Flow boiling in microchannels is an effective method for dissipating high heat fluxes. However, two-phase heat sink operation during transient heating conditions remains relatively unexplored. In Part 1 of this two-part study, the dynamic response of flow boiling to a single heat flux pulse was experimentally studied. In this Part 2, the effect of heating pulse frequency on microchannel flow boiling is explored when a time-periodic series of pulses is applied to the channel. HFE-7100 is driven through a single $500 \mu \mathrm{m}$-diameter glass microchannel using a constant pressure reservoir. A thin indium tin oxide layer on the outside surface of the microchannel enables simultaneous transient heating and flow visualization. High-frequency measurements of heat flux, wall temperature, pressure drop, and mass flux are synchronized to the flow visualizations to characterize the boiling process. A square-wave heating profile is used with pulse frequencies ranging from 0.1 to $100 \mathrm{~Hz}$ and three different heat fluxes levels $(15,75$,
\end{abstract}

\footnotetext{
1 Submitted for review to International Journal of Heat and Mass Transfer as Part 2 of two companion papers

2 Currently NRC/NRL Cooperative Research Associate, U.S. Naval Research Laboratory, Washington D.C.

3 Currently President, University of Vermont

* Corresponding authors

E-mail addresses: kingston@purdue.edu (T.A. Kingston), jaweibel@purdue.edu (J.A. Weibel), sureshg@purdue.edu (S.V. Garimella)
} 
and $150 \mathrm{~kW} / \mathrm{m}^{2}$ ). Three different time-periodic flow boiling fluctuations were observed for the heat flux levels and pulse frequencies investigated in this study: flow regime transitions, pressure drop oscillations, and heating pulse propagation. For heat flux pulses between 15 and $75 \mathrm{~kW} / \mathrm{m}^{2}$ and heating pulse frequencies above $1 \mathrm{~Hz}$, time-periodic flow regime transitions between single-phase and two-phase flow are reported. For heating profiles involving 150 $\mathrm{kW} / \mathrm{m}^{2}$ heat flux pulses, fluid in the microchannel is always boiling and thus the flow regime transitions are eliminated. For heating pulse frequencies between approximately 1 and $10 \mathrm{~Hz}$, the thermal and flow fluctuations are heavily coupled to the heating characteristics, forcing the pressure drop instability frequency to match the heating frequency. Outside this heating pulse frequency range, the pressure drop instability occurs at the intrinsic frequency of the system. For heating pulse frequencies above $25 \mathrm{~Hz}$, the microchannel wall attenuates the transient heating profile and the fluid essentially experiences a constant heat flux.

Keywords: flow boiling, microchannel, pressure drop oscillations, pulse frequency, transient heating

\section{Highlights}

- The effects of heating pulse frequency on flow boiling are studied experimentally.

- Flow boiling performance and transient heating characteristics are heavily coupled.

- Time-periodic flow regime transitions can occur for heating pulse frequencies $>1 \mathrm{~Hz}$.

- Pressure drop oscillations sync to the transient heating profile for $1<f<10 \mathrm{~Hz}$.

- Above a heating pulse frequency of $25 \mathrm{~Hz}$, the fluid effectively experiences a constant heat flux. 


$\begin{array}{ll}\text { Nomenclature } \\ f & \text { frequency } \\ G & \text { mass flux } \\ \Delta p & \text { pressure drop across the microchannel } \\ t & \text { time } \\ T_{\text {wall }} & \text { microchannel outside wall temperature } \\ q_{\text {net }} & \text { net heat flux into the microchannel } \\ q_{\text {net,low }} & \text { low heating pulse level } \\ q_{\text {net, high }} & \text { high heating pulse level }\end{array}$

\section{Introduction}

Microchannel flow boiling is regarded as one of the most promising two-phase thermal management strategies for high-heat-flux dissipation. Yet, commonly encountered flow boiling instabilities result in large thermal and hydrodynamic oscillations that can influence the heat transfer mechanisms and reduce heat sink performance, as reviewed in Refs. [1-3]. One commonly encountered flow boiling instability of particular relevance to the current study is pressure drop oscillations, which result from the interaction between vapor within a heated channel and system compressibility [4]. To quantify the impact of pressure drop oscillations on flow boiling performance, Guo et al. [5] conducted experiments with steam-water flow in a helical-coiled tube. A surge tank was inserted into the flow loop to introduce a compressible volume and promote pressure drop oscillations; oscillations were not observed in tests without the surge tank. It was shown that flow oscillations induced by the pressure drop instability significantly reduced the time-averaged heat transfer coefficient (HTC).

The effect of artificially induced flow oscillations on flow boiling performance has also been studied. Park et al. [6] recently induced flow oscillations of R134a in a single, heated stainless steel tube by controlling the pump speed in a sinusoidal manner. The amplitude and 
period of the flow rate oscillations were varied and the time-averaged HTC was measured. It was shown that beyond a particular threshold, the HTC deteriorated with increasing oscillation amplitude and period. Using the same test facility, Sorum and Dorao [7] demonstrated that density wave oscillations reduce the time-averaged HTC, and this phenomenon is exacerbated when the inlet pressure, mass flow rate, or fluid inlet subcooling are reduced. Flow boiling instabilities can also result in premature critical heat flux [8]. To better understand the mechanisms causing this phenomenon, Ozawa et al. [9] conducted flow boiling experiments with water in a single, heated stainless steel tube. A piston-cylinder device was coupled to a motor to induce sinusoidal flow rate oscillations with various amplitudes and periods. It was shown that critical heat flux decreased with increasing amplitude and oscillation period, and was about $40 \%$ of that when flow rate oscillations were not present.

Thermal and flow oscillations resulting from flow boiling instabilities make design and prediction of two-phase heat sink performance difficult, even under steady heating conditions. This is further complicated by the time-varying heat loads typically generated by many highheat-flux devices that have inherently transient operating conditions (e.g., power amplifiers, central processing units). These transient heating conditions can have significant implications on the flow and heat transfer behavior and lead to reduced device performance. Miler et al. [10] studied flow boiling in a single microchannel and found that for the same total heater power, pulsed heating conditions cause an increase in the time-averaged device temperature. Aguiar and Ribatski [11] investigated the effects of transient heat flux variations on wall temperature and HTC by performing flow boiling experiments at various heat and mass fluxes and inlet vapor qualities for R134a in a $1.1 \mathrm{~mm}$ diameter stainless steel tube. Sinusoidal, square, and sawtooth transient heating profiles were applied to a $10 \mathrm{~mm}$ hotspot that was centrally located along a 90 
$\mathrm{mm}$ heated region of the tube. Parametric trends were reported for various transient hotspot heating waveforms, frequencies, and amplitudes. Huang et al. [12] studied the effects of periodic heat pulses on the base temperature of a two-phase parallel channel heat sink. The effects of working fluid, heat flux, mass flux, inlet subcooling, and outlet saturation temperature were investigated. The transient base temperature was measured using an infrared camera and was synchronized to flow visualizations recorded with a high-speed optical camera. Near the inlet of the channels, the flow oscillated between single-phase flow and subcooled boiling, resulting in large oscillation amplitudes and a higher overall temperature. Further downstream, continuous flow boiling was observed thus reducing the oscillation amplitude and the overall temperature. For the range of conditions tested, the mass flux and heating pulse frequency were insignificant.

While prior studies have quantified the effects of transient heating on wall temperature and heat transfer coefficient, the combined thermal and hydrodynamic response and the coupling between flow boiling instabilities and transient heating conditions remains relatively unknown. In Part 1 of this two-part study [13], the effects of a single heat flux pulse on the resulting thermal and hydrodynamic characteristics of flow boiling in a microchannel were reported. Here in Part 2, time-periodic heat flux pulses are applied to the microchannel in the form of a square wave having frequencies between 0.1 and $100 \mathrm{~Hz}$. The thermal and flow dynamics are investigated using synchronized flow visualizations and high-frequency sensor measurements, which enables the coupling between flow boiling instabilities and transient heating conditions to be quantified. 


\section{Experimental methods}

The experimental facility is described in Part 1 [13] of this two-part study; a brief description is provided here. Degassed, dielectric HFE-7100 liquid is delivered to the testsection microchannel, shown in Figure 1, using a constant pressure reservoir. The liquid flow rate and the test section outlet saturation pressure can be adjusted using needle valves placed in the open flow loop. The liquid volumetric flow rate is measured using an upstream liquid flow meter. The liquid is preheated to the desired inlet temperature immediately upstream of the test section using a constant-temperature circulating bath. The inlet and outlet fluid temperatures are measured immediately upstream and downstream of the test section. The inlet and outlet pressure in the microchannel are measured using separate pressure transducers; the pressure drop across the microchannel is taken as the difference between the inlet and outlet pressure measurements.

The test-section microchannel is mounted horizontally between two polyetheretherketone (PEEK) connectors, which serve as the inlet and outlet plenums (Figure 1). The circular crosssection microchannel is made of borosilicate glass with an inside diameter of $500 \mu \mathrm{m}$ and a wall thickness of $100 \mu \mathrm{m}$. The thin wall enables transient heating profiles to propagate to the coolant, as may occur in embedded two-phase heat sinks $[14,15]$. The outside surface of the microchannel is coated with a $100 \mathrm{~nm}$-thick layer of indium tin oxide (ITO). The ITO layer is optically transparent and electrically conductive, enabling simultaneous Joule heating and visualization of the two-phase flow. 


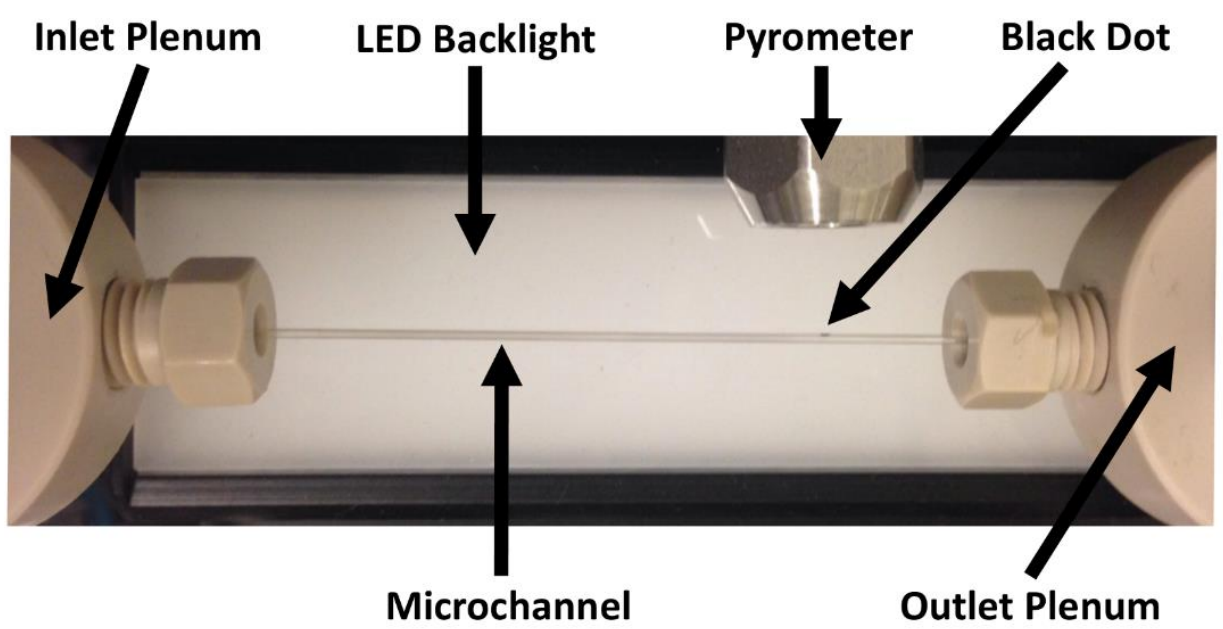

Figure 1. Test-section microchannel and surrounding equipment.

Power is supplied to the ITO coating using an adjustable direct current power supply. The total heating power (which includes power loss to the ambient that is quantified using the procedure described in Part 1 [13]) applied to the test section is quantified by measuring the voltage drop across and current through the ITO microchannel coating. A solid-state switch is wired in parallel to several potentiometers to allow transient switching between two different power levels and fine adjustment of the magnitudes. The switch is activated by an output voltage signal from a data acquisition (DAQ) unit that is controlled using LabVIEW. The outside wall temperature of the microchannel is measured at a single fixed location using a pyrometer coupled to a focusing lens. The pyrometer is focused on a black dot painted on the outside surface of a channel. Test-section heat flux, wall temperature, pressure drop, and mass flux measurements are obtained at 2,500 $\mathrm{Hz}$ using the high-frequency DAQ unit.

The entire heated region of the microchannel is visualized from the top using a highspeed camera coupled to a macro lens. The bottom side of the channel is uniformly illuminated using a light-emitting diode backlight. High-speed optical images are synchronized to heat flux, 
wall temperature, pressure drop, and mass flux measurements using a pulse generator to simultaneously trigger the camera and high-frequency DAQ unit.

Three different heat flux levels are selected to construct the transient heating profiles based on the time-averaged data described in Part 1 of this study [13]. The selected levels are: $q_{n e t}=15,75$, and $150 \mathrm{~kW} / \mathrm{m}^{2}$, which under steady heating conditions respectively correspond to single-phase flow, continuous flow boiling, and what would be dryout (if operated at $150 \mathrm{~kW} / \mathrm{m}^{2}$ continuously). Once the desired flow conditions are set (reservoir pressure of $190 \mathrm{kPa}$, mass flux of $400 \mathrm{~kg} / \mathrm{m}^{2} \mathrm{~s}$, and test section outlet pressure of $114 \mathrm{kPa}$ ) using the same procedure described in Part 1 of this study [13], a square-wave heating profile is applied to the microchannel. The different square-wave profiles investigated are defined by operating scenarios and frequencies shown in Table 1. For each operating scenario, the square-wave profile switches between two of the selected levels, noted as the low and high heating pulse levels in the table. For operating scenarios 1 and 2, a 50\% duty cycle (defined as the ratio of time at the high heating pulse level to total time for each period) is used whereas for operating scenario 3, composed of the two higher heating levels, the duty cycle is reduced to $25 \%$ to keep the transient wall temperature below 200 ${ }^{\circ} \mathrm{C}$. For each operating scenario, tests are initiated at the highest heating pulse frequency (100 $\mathrm{Hz}$ ) and reduced either to $0.1 \mathrm{~Hz}$ or until the transient wall temperature measured during the tests approaches the $200{ }^{\circ} \mathrm{C}$ limit; the lowest heating pulse frequency for operating scenarios 2 and 3 was $0.8 \mathrm{~Hz}$. The heating pulse frequency range spans three orders of magnitude and is approximately centered around the thermal time constant of the test section microchannel, which was experimentally measured to be $0.43 \mathrm{~s}$ in Part 1 of this study [13]. For each operating scenario, sensor data and optical images are recorded for $12 \mathrm{~s}$ at 2,500 Hz and 30,000 frames per 
second, respectively. The data reduction methods used to process the acquired data are the same as those described in Part 1 of this study [13].

Table 1. Operating conditions used in this study to perform time-periodic heating of the microchannel.

\begin{tabular}{ccccc}
\hline & $\begin{array}{c}\text { Low Heating } \\
\text { Pulse Level, } \\
q_{\text {net,low }} \\
\text { Operating } \\
\text { Scenario }\end{array}$ & $\begin{array}{c}\text { High Heating } \\
\text { Pulse Level, } \\
q_{\text {net, } \text { high }} \\
{\left[\mathrm{kW} / \mathrm{m}^{2}\right]}\end{array}$ & $\begin{array}{c}\text { Duty } \\
\text { Cycle }\end{array}$ & \\
\hline 1 & 15 & 75 & 50 & $0.1,0.2,0.5,1,2,5,10,15,20,25,50,100$ \\
\hline 2 & 15 & 150 & 50 & $0.8,1,2,3,4,5,10,15,20,25,50,100$ \\
\hline 3 & 75 & 150 & 25 & $0.8,1,2,3,4,5,10,15,20,25,50,100$ \\
\hline
\end{tabular}

\section{Results and discussion}

\subsection{Summary of transient heating-induced fluctuations}

The heating pulse levels and frequencies investigated in this study (Table 1) resulted in three different time-periodic flow boiling fluctuations: flow regime transitions, pressure drop oscillations, and heating pulse propagation. In this study, flow regime transitions are defined as time-periodic transitions between single-phase flow and two-phase flow that arise due to lowfrequency $(\sim 1 \mathrm{~Hz})$ compressibility effects within the flow loop at heat fluxes just beyond that required to induce boiling and cause relatively cool incoming liquid to quench the channel wall and arrest boiling. These flow regime transitions are distinct from those directly induced by increases or decreases in the heat flux level that induce or arrest boiling. Pressure drop oscillations occur due to interaction and delayed feedback between vapor within the heated channel and upstream compressibility. These oscillations cause time-periodic fluctuations in the wall temperature, pressure drop, and mass flux, and occur at a frequency higher than the flow regime transitions. Heating pulse propagation is defined as identifiable thermal and flow 
fluctuations at the heating pulse frequency that result from the applied heat flux propagating through the microchannel wall and into the fluid.

Not all of these time-periodic fluctuations occur at each operating condition; Figure 2 provides three summary charts that describe which of the three time-periodic fluctuations were observed at each operating condition. Each chart is labeled on the left with the heating pulse levels corresponding to the three different operating scenarios; the duty cycle for each combination of heating pulse levels is also shown. The applied heating pulse frequency is shown along the top horizontal axis. Within each chart, colored horizontal bars correspond to the range of frequencies over which each type of fluctuation was observed: a blue bar indicates flow regime transitions, a green bar indicates pressure drop oscillations, and a red bar indicates heating pulse propagation, as noted by labels to the right of each chart. Operating frequency ranges without a colored horizontal bar indicate that these time-periodic fluctuations were not observed; fading of the bar from colored to white indicates a gradual attenuation of the fluctuations. Each dashed vertical line in Figure 2 indicates a specific combination of heating pulse levels and frequency tested in this study (Table 1). For example, at a heating pulse frequency of $1 \mathrm{~Hz}$, tests are performed for operating scenarios 1,2, and 3, which have respective duty cycles of $50 \%, 50 \%$, and $25 \%$. These summary charts in Figure 2 were constructed from the data from all tests in Table 1.

In this study, flow regime transitions only occurred when the heat flux was pulsed between 15 and $75 \mathrm{~kW} / \mathrm{m}^{2}$ (operating scenario 1) and the heating pulse frequency was greater than or equal to the intrinsic frequency of the flow regime transitions $(f \geq 1 \mathrm{~Hz})$, as shown in Figure 2. This intrinsic frequency of the flow regime transitions is dependent on the system configuration (e.g., thermal mass of the test section, upstream compressibility, etc.) and 
operating conditions (e.g., flow rate, heat flux, etc.). For heating pulse frequencies less than the intrinsic frequency of the flow regime transitions $(f<1 \mathrm{~Hz})$, boiling incipience would only occur when switched to $q_{n e t}=75 \mathrm{~kW} / \mathrm{m}^{2}$ and boiling would stop when switched back to $q_{\text {net }}=15$ $\mathrm{kW} / \mathrm{m}^{2}$. Thus, the mechanism causing the flow to transition between single-phase and two-phase flow under these heating conditions $(f<1 \mathrm{~Hz})$ is different from that for the flow regime transitions. Flow regime transitions were not observed for any heating frequency where the heat flux was pulsed between 15 and $150 \mathrm{~kW} / \mathrm{m}^{2}$ or 75 to $150 \mathrm{~kW} / \mathrm{m}^{2}$ because the effective heat flux experienced by the channel is large enough to continuously maintain boiling.

For all operating scenarios and heating pulse frequencies tested in this study, timeperiodic pressure drop oscillations resulting from the pressure drop instability were observed. At intermediate heating pulse frequencies $(1<f<10 \mathrm{~Hz})$, the heating profile is heavily coupled to the cooling performance, and the pressure drop oscillation frequency exactly aligns with the heating pulse frequency. At relatively low $(<1 \mathrm{~Hz})$ and high $(>10 \mathrm{~Hz})$ heating pulse frequencies, pressure drop oscillations occurred at the intrinsic frequency of the pressure drop instability; this intrinsic pressure drop instability frequency is also dependent on system design and operating conditions, and will be shown to significantly change with heating level in Section 3.2 .

Time-periodic heating of the microchannel resulted in thermal and flow fluctuations at the heating frequency only when the heating frequency was less than approximately $25 \mathrm{~Hz}$. Above this cutoff frequency, the heating pulse frequency was too fast to propagate to the fluid and was effectively damped by the microchannel wall. 


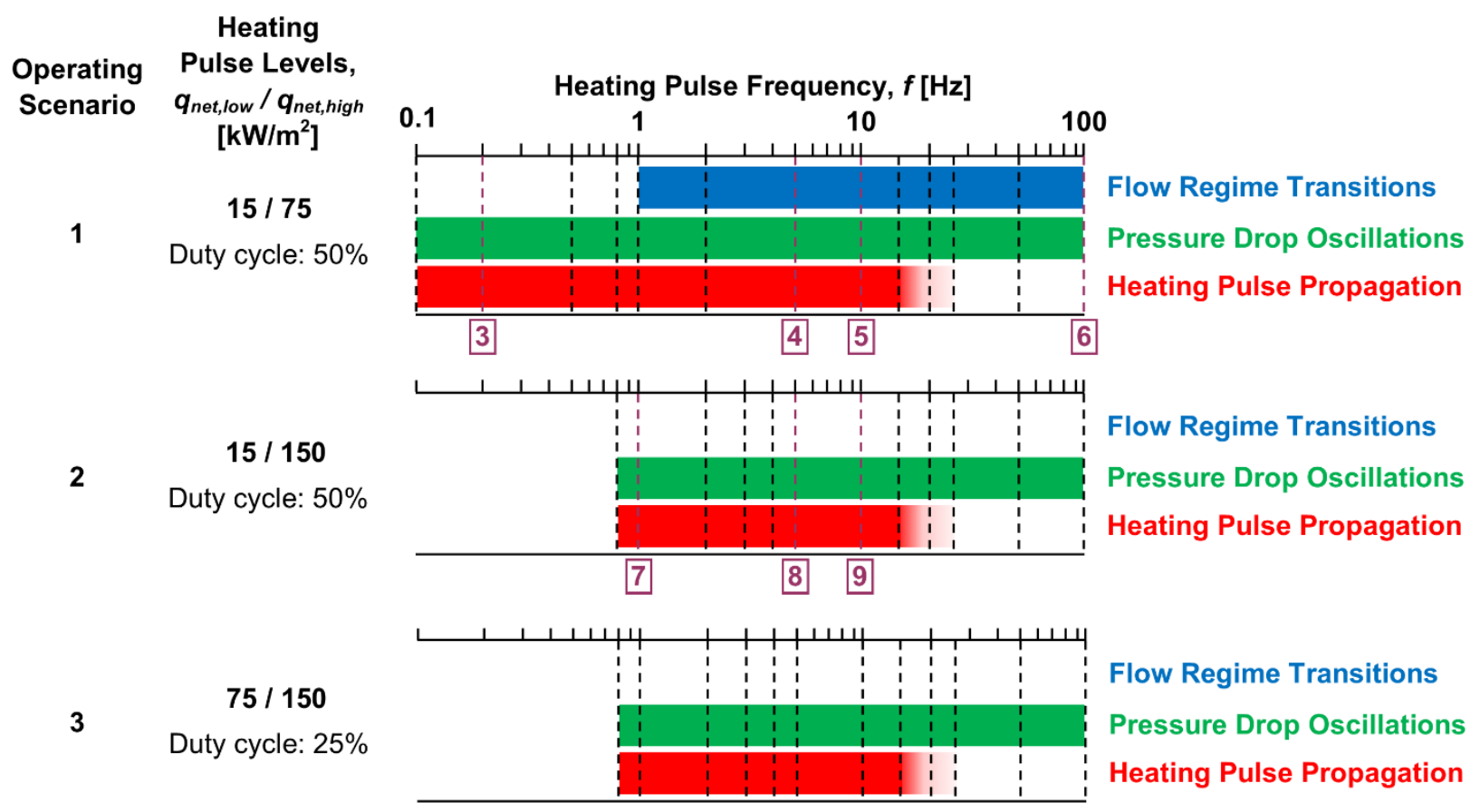

Figure 2. Summary charts for each operating scenario showing the range of heating pulse frequencies over which flow regime transitions and pressure drop oscillations are observed, as well as whether the heating pulses propagate to the fluid. Colored horizontal bars indicate the frequency range associated with each characteristic fluctuation labeled in the matching font color. Dashed vertical lines indicate the specific combinations of heating pulse levels and frequencies that were tested (Table 1). The numbers inscribed in the boxes (3 through 9) denote the selected operating conditions detailed in Section 3.2 and correspond to Figure 3 through Figure 9.

Analysis of the time and spectral domains for four heating pulse frequencies $(0.2,5,10$, and $100 \mathrm{~Hz})$ for operating scenario $1\left(q_{\text {net,low }}=15 / q_{\text {net,high }}=75 \mathrm{~kW} / \mathrm{m}^{2}\right)$, and three heating pulse frequencies $(1,5$, and $10 \mathrm{~Hz})$ for operating scenario $2\left(q_{\text {net, low }}=75 / q_{\text {net, high }}=150 \mathrm{~kW} / \mathrm{m}^{2}\right)$, are provided in Section 3.2 to illustrate the effect of heating pulse frequency and time-periodic fluctuations that are summarized in Figure 2. Because operating scenarios 2 and 3 resulted in 
continuous boiling for all heating pulse frequencies, the observed time-periodic fluctuations were similar in both cases; analysis of the time and spectral domain for operating scenario 3 is thus not shown. A summary of the primary observations and takeaways from each of these seven selected operating conditions is shown in Table 2. Figure 3-Figure 9 (one figure for each selected operating condition in Section 3.2) show (a) the sensor measurements in the time domain and (b) their corresponding normalized spectral density in the frequency domain as determined using a fast Fourier transform. Videos of the synchronized flow visualizations and sensor measurements for each selected operating condition corresponding to Figure 3-Figure 9 are available online in the Supplementary Materials. 
Table 2. Summary of the primary observations and takeaways from selected operating conditions corresponding to Figures 3-9.

\begin{tabular}{|c|c|c|c|c|c|c|c|c|}
\hline $\begin{array}{l}\text { Operating } \\
\text { Scenario }\end{array}$ & $\begin{array}{l}\text { Low Heating } \\
\text { Pulse Level, } \\
q_{\text {net, low }} \\
{\left[\mathrm{kW} / \mathrm{m}^{2}\right]}\end{array}$ & $\begin{array}{l}\text { High Heating } \\
\text { Pulse Level, } \\
q_{\text {net, high }} \\
{\left[\mathrm{kW} / \mathrm{m}^{2}\right]}\end{array}$ & $\begin{array}{l}\text { Heating Pulse } \\
\text { Frequency, } \\
\quad f[\mathrm{~Hz}]\end{array}$ & $\begin{array}{c}\text { Corresponding } \\
\text { Figure }\end{array}$ & $\begin{array}{l}\text { Flow } \\
\text { Regime } \\
\text { Transitions? }\end{array}$ & $\begin{array}{l}\text { Pressure } \\
\text { Drop } \\
\text { Oscillations? }\end{array}$ & $\begin{array}{l}\text { Heating } \\
\text { Pulse } \\
\text { Propagation? }\end{array}$ & Primary Observations and Takeaways \\
\hline \multirow{4}{*}{1} & \multirow{4}{*}{15} & \multirow{4}{*}{75} & 0.2 & 3 & No & Yes & Yes & $\begin{array}{l}\text { - Flow regime transitions resulting from compressibility effects } \\
\text { do not occur because the mechanism causing boiling is the } \\
\text { changing of the heat flux level } \\
\text { - Pressure drop oscillations occur at } 4 \mathrm{~Hz} \text { during instances when } \\
q_{\text {net }}=75 \mathrm{~kW} / \mathrm{m}^{2} \\
\text { - Individual heating pulses propagate through the microchannel } \\
\text { wall to the fluid because the heating pulse frequency is low }\end{array}$ \\
\hline & & & 5 & 4 & Yes & Yes & Yes & $\begin{array}{l}\text { - Propagation of the heating pulse frequency forces the } \\
\text { pressure drop oscillations to occur at exactly } 5 \mathrm{~Hz} \\
\text { - Flow regime transitions occur at } 1 \mathrm{~Hz} \text { and are superimposed } \\
\text { with pressure drop oscillations }\end{array}$ \\
\hline & & & 10 & 5 & Yes & Yes & Yes & $\begin{array}{l}\text { - Flow regime transitions occur at } 1 \mathrm{~Hz} \text { and are superimposed } \\
\text { with } 4 \mathrm{~Hz} \text { pressure drop oscillations } \\
\text { - Heating pulses propagate to the fluid at } 10 \mathrm{~Hz} \text { and appear in } \\
\text { all sensor measurements }\end{array}$ \\
\hline & & & 100 & 6 & Yes & Yes & No & $\begin{array}{l}\text { - The high heating pulse frequency cannot propagate to the } \\
\text { fluid, causing the channel to be essentially heated at a } \\
\text { constant heat flux of } q_{\text {net }}=(15+75) / 2=45 \mathrm{~kW} / \mathrm{m}^{2} \\
\text { - Flow regime transitions occur at } 1 \mathrm{~Hz} \text { and are superimposed } \\
\text { with } 7 \mathrm{~Hz} \text { pressure drop oscillations }\end{array}$ \\
\hline \multirow{3}{*}{2} & \multirow{3}{*}{15} & \multirow{3}{*}{150} & 1 & 7 & No & Yes & Yes & $\begin{array}{l}\text { - The fluid is boiling continuously for all heating pulse } \\
\text { frequencies for operating scenario } 2 \\
\text { - Pressure drop oscillations occur at } 32 \mathrm{~Hz} \text { during instances } \\
\text { when } q_{\text {net }}=150 \mathrm{~kW} / \mathrm{m}^{2}\end{array}$ \\
\hline & & & 5 & 8 & No & Yes & Yes & $\begin{array}{l}\text { - The heating pulses are propagating and force the pressure } \\
\text { drop oscillations to occur at exactly } 5 \mathrm{~Hz}\end{array}$ \\
\hline & & & 10 & 9 & No & Yes & Yes & $\begin{array}{l}\text { - The heating pulses are propagating to the fluid and appear in } \\
\text { all sensor measurements } \\
\text { - Pressure drop oscillations are occurring at } 5 \mathrm{~Hz}\end{array}$ \\
\hline
\end{tabular}

The primary observations and takeaways for operating scenario 3 are not listed because they are the same as for operating scenario 2 


\subsection{Time and spectral domain analysis}

Shown in Figure 3 are the sensor measurements for heat flux pulses between 15 and 75 $\mathrm{kW} / \mathrm{m}^{2}$ at $0.2 \mathrm{~Hz}$ and the corresponding normalized spectral density of the signals as determined using a fast Fourier transform. The amplitude of the spectral density resulting from the transformation is normalized relative to the maximum spectral density of each sensor measurement. For this case, the relatively low-frequency heat flux pulses are effectively isolated from one another and the flow reaches a time-periodic boiling condition during each pulse to 75 $\mathrm{kW} / \mathrm{m}^{2}$ and returns to a steady single-phase flow regime between each pulse. As shown in Figure 3a, prior to the heat flux pulse, the sensor measurements are steady in time ( $\Delta p=2 \mathrm{kPa}, G$ $=410 \mathrm{~kg} / \mathrm{m}^{2} \mathrm{~s}$, and $T_{\text {wall }}=90^{\circ} \mathrm{C}$ ) and the flow is in the single-phase regime. Once the pulse begins at $t=0.5 \mathrm{~s}$, the wall temperature increases and boiling is initiated in the channel shortly thereafter at $t=0.62 \mathrm{~s}$. At approximately $t=1.7 \mathrm{~s}$, a time-periodic wall temperature oscillating around a mean of $\sim 115^{\circ} \mathrm{C}$ is observed, in addition to corresponding time-periodic oscillations in the pressure drop and mass flux. These oscillations in the wall temperature, pressure drop, and mass flux are caused by the pressure drop instability. Spectral analysis of the sensor measurements, as shown in Figure 3b, indicates that the primary frequency is $0.2 \mathrm{~Hz}$, corresponding to the heating frequency. The smaller peaks that decay with increasing frequency in the normalized spectral density at multiples of the $0.2 \mathrm{~Hz}$ heating pulse frequency are harmonics of the spectral analysis. If the spectral analysis is applied only to data during the heat flux pulse, an intrinsic pressure drop oscillation frequency of $4 \mathrm{~Hz}$ is identified (not shown in Figure 3). Because boiling is being induced or arrested when the heat flux changes between $q_{n e t}$ $=15 \mathrm{~kW} / \mathrm{m}^{2}$ and $q_{n e t}=75 \mathrm{~kW} / \mathrm{m}^{2}$, rather than occurring due to interaction with the upstream 
compressible volume, the changes between single-phase flow and two-phase flow are not classified as flow regime transitions.

(a)
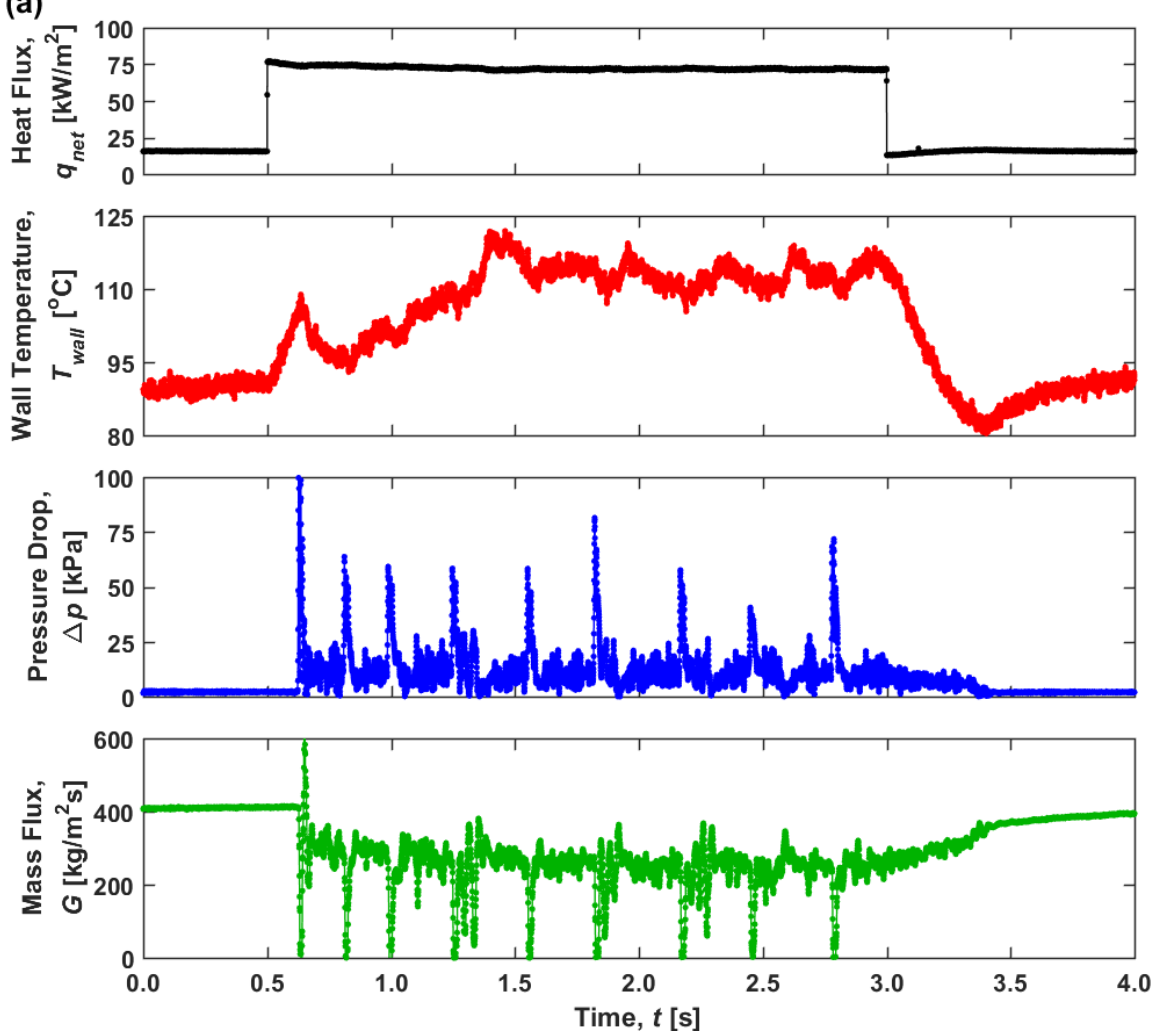
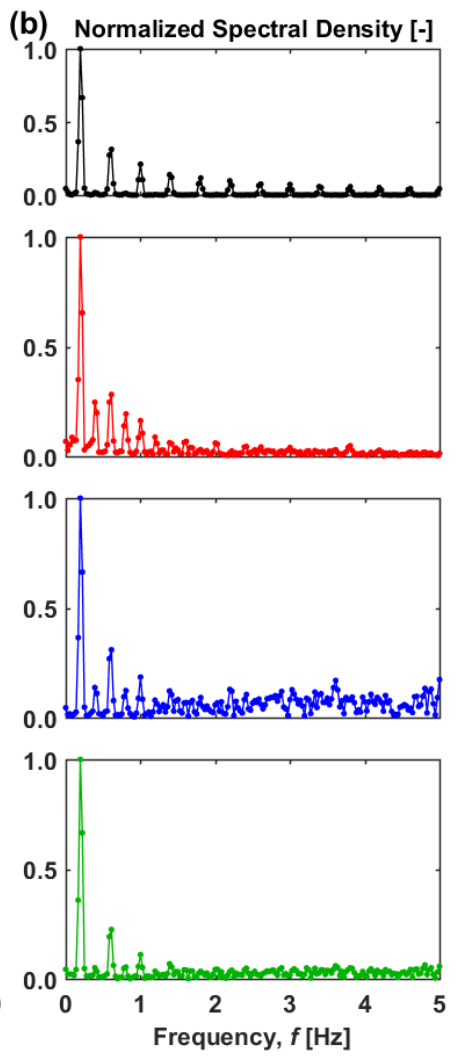

Figure 3. (a) Heat flux, wall temperature, pressure drop, and mass flux as a function of time for heat flux pulses between 15 and $75 \mathrm{~kW} / \mathrm{m}^{2}$ (operating scenario 2) at $0.2 \mathrm{~Hz}$. A corresponding video of the synchronized flow visualizations and sensor measurements is available online in the Supplementary Materials (Video S1). (b) Normalized spectral density of the sensor measurements.

Sensor measurements for heat flux pulses between 15 and $75 \mathrm{~kW} / \mathrm{m}^{2}$ at $5 \mathrm{~Hz}$ and the corresponding normalized spectral density of the signals are shown in Figure 4. At this frequency, the fluid in the channel is always boiling. The close proximity of the heating pulse frequency $(5 \mathrm{~Hz})$ to the intrinsic pressure drop oscillation frequency under constant heating 
conditions (observed to be in the range of 4-7 $\mathrm{Hz}$ for this operating condition) causes the pressure drop oscillations to occur in exact alignment with the heating pulse frequency at $5 \mathrm{~Hz}$, as indicated by the large, distinct spike in the normalized spectral density in Figure 4b.

Meanwhile, time-periodic flow regime transitions are also occurring at $1 \mathrm{~Hz}$, as indicated by the second spike in the normalized spectral density for the wall temperature in Figure $4 \mathrm{~b}$. When the flow transitions to single-phase flow, a relatively large spike in the wall temperature occurs, as shown in Figure $4 \mathrm{a}$ at $t=0.4$ and $1.4 \mathrm{~s}$. These flow regime transitions are caused by depressurization of the upstream compressible volume, which surges cooler liquid through the channel and suppresses nucleation, causing a transition to single-phase liquid flow. The wall temperature of the channel then increases until the fluid begins boiling, and the process repeats. This behavior is clearly visible in Supplementary Video S2. 
(a)
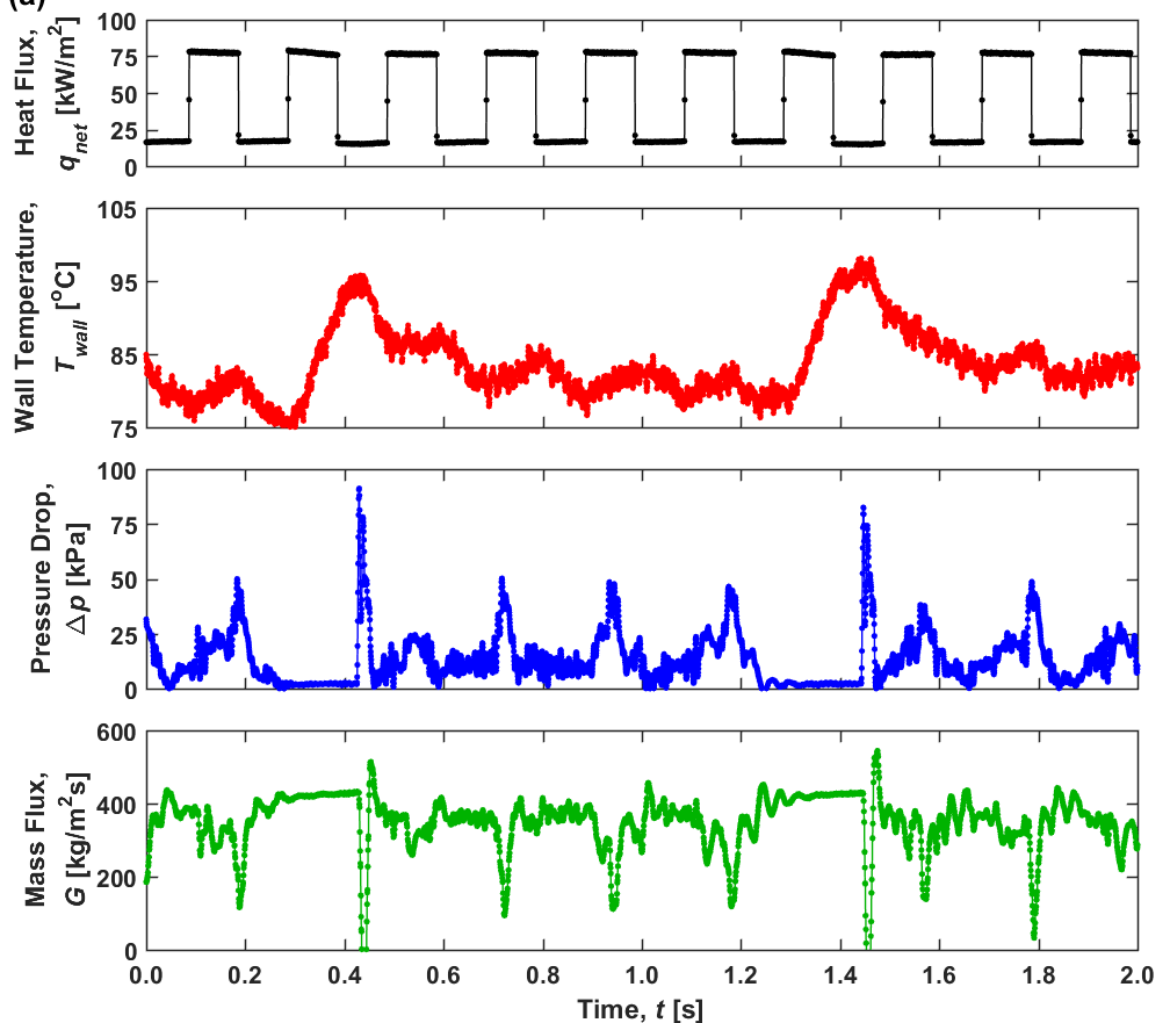
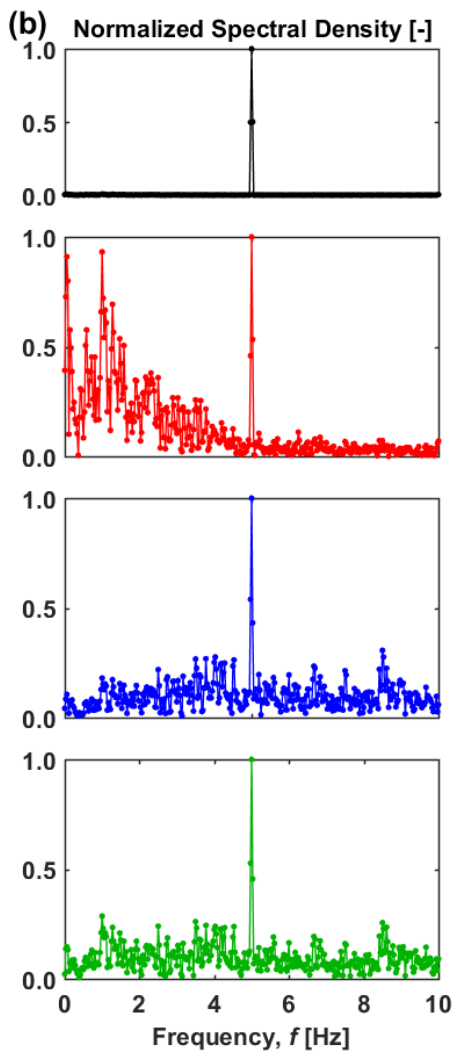

Figure 4. (a) Heat flux, wall temperature, pressure drop, and mass flux as a function of time for heat flux pulses between 15 and $75 \mathrm{~kW} / \mathrm{m}^{2}$ (operating scenario 1) at $5 \mathrm{~Hz}$. A corresponding video of the synchronized flow visualizations and sensor measurements is available online in the Supplementary Materials (Video S2). (b) Normalized spectral density of the sensor measurements.

Displayed in Figure 5 are the sensor measurements for heat flux pulses between 15 and $75 \mathrm{~kW} / \mathrm{m}^{2}$ at $10 \mathrm{~Hz}$ and the corresponding normalized spectral density of the signals. The heating pulse frequency is still able to propagate through the microchannel wall at this higher frequency; a spike in the normalized spectral density for each sensor appears at $f=10 \mathrm{~Hz}$. However, the heating pulse frequency is too fast to force the pressure drop oscillations to occur at this frequency. The pressure drop oscillations instead occur at the intrinsic frequency of $\sim 4$ $\mathrm{Hz}$, as indicated by the small peak in Figure $5 \mathrm{~b}$ at $4 \mathrm{~Hz}$ and confirmed by the flow visualizations. 
Meanwhile, flow regime transitions are also occurring, as indicated by the large periodic increases in the wall temperature Figure $5 \mathrm{a}$ and the large spike at $1 \mathrm{~Hz}$ in the wall temperature normalized spectral density in Figure $5 b$.

(a)
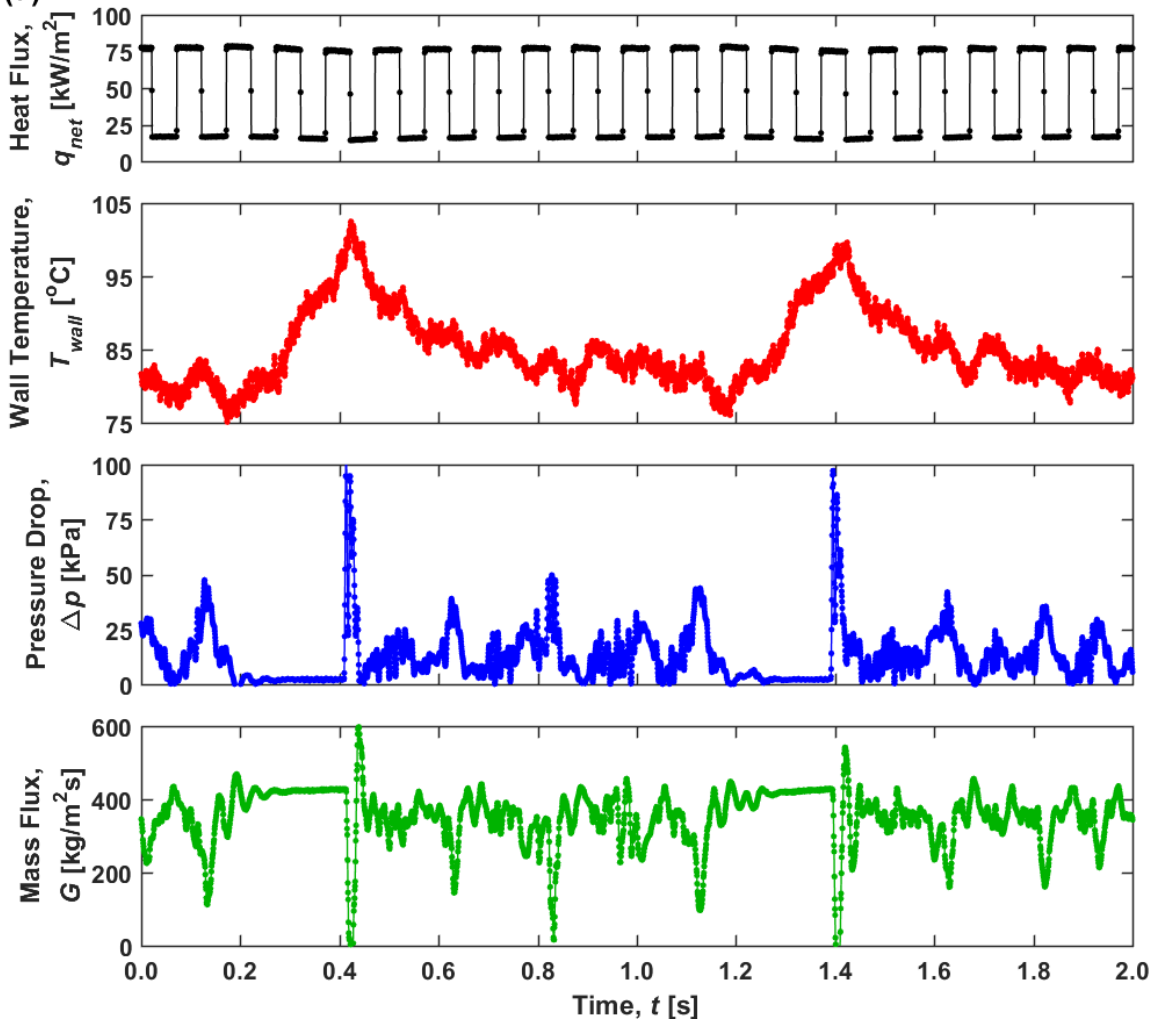

(b) Normalized Spectral Density [-]
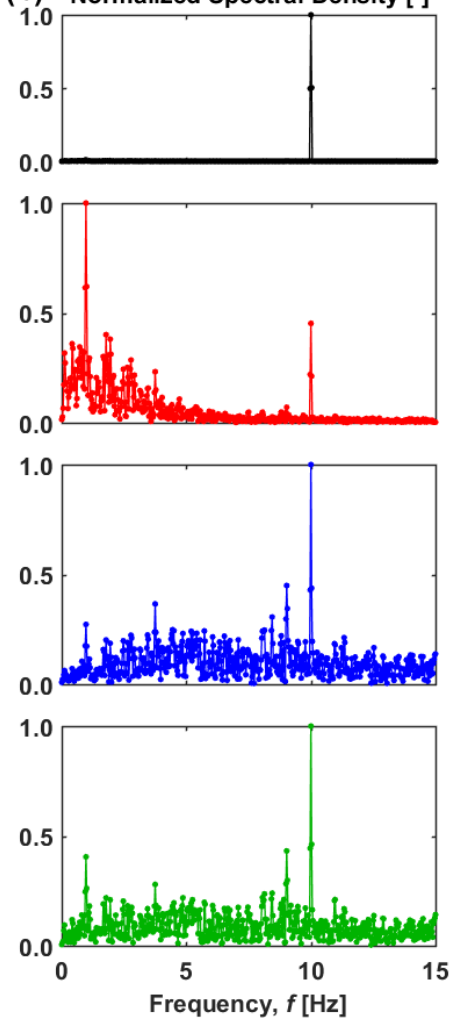

Figure 5. (a) Heat flux, wall temperature, pressure drop, and mass flux as a function of time for heat flux pulses between 15 and $75 \mathrm{~kW} / \mathrm{m}^{2}$ (operating scenario 1) at $10 \mathrm{~Hz}$. A corresponding video of the synchronized flow visualizations and sensor measurements is available online in the Supplementary Materials (Video S3). (b) Normalized spectral density of the sensor measurements.

Sensor measurements for heat flux pulses between 15 and $75 \mathrm{~kW} / \mathrm{m}^{2}$ at $100 \mathrm{~Hz}$ and the corresponding normalized spectral density of the signals are shown in Figure 6. At this much higher frequency of $f=100 \mathrm{~Hz}$, the heat flux profile changes so quickly that the microchannel wall entirely damps the heating transients and the channel behaves as if it were effectively heated 
at a steady heat flux of $q_{n e t}=(15+75) / 2=45 \mathrm{~kW} / \mathrm{m}^{2}$. It was shown in Part 1 of this two-part study [13] that constant heating at $45 \mathrm{~kW} / \mathrm{m}^{2}$ results in time-periodic flow regime transitions, which are indicated in Figure 6a by the large spikes in the wall temperature and pressure drop (and large dips in the mass flux) at $t=0.47$ and $1.70 \mathrm{~s}$. In between instances of single-phase flow, when the fluid is boiling, pressure drop oscillations are observed, as shown by the smallermagnitude, higher-frequency fluctuations in the wall temperature, pressure drop, and mass flux in Figure 6a. Spectral analysis of the sensor measurements clearly shows that the heating pulse frequency of $100 \mathrm{~Hz}$ does not propagate to the fluid; the flow regime transitions and pressure drop oscillations are occurring at $1 \mathrm{~Hz}$ and $7 \mathrm{~Hz}$, respectively.

(a)
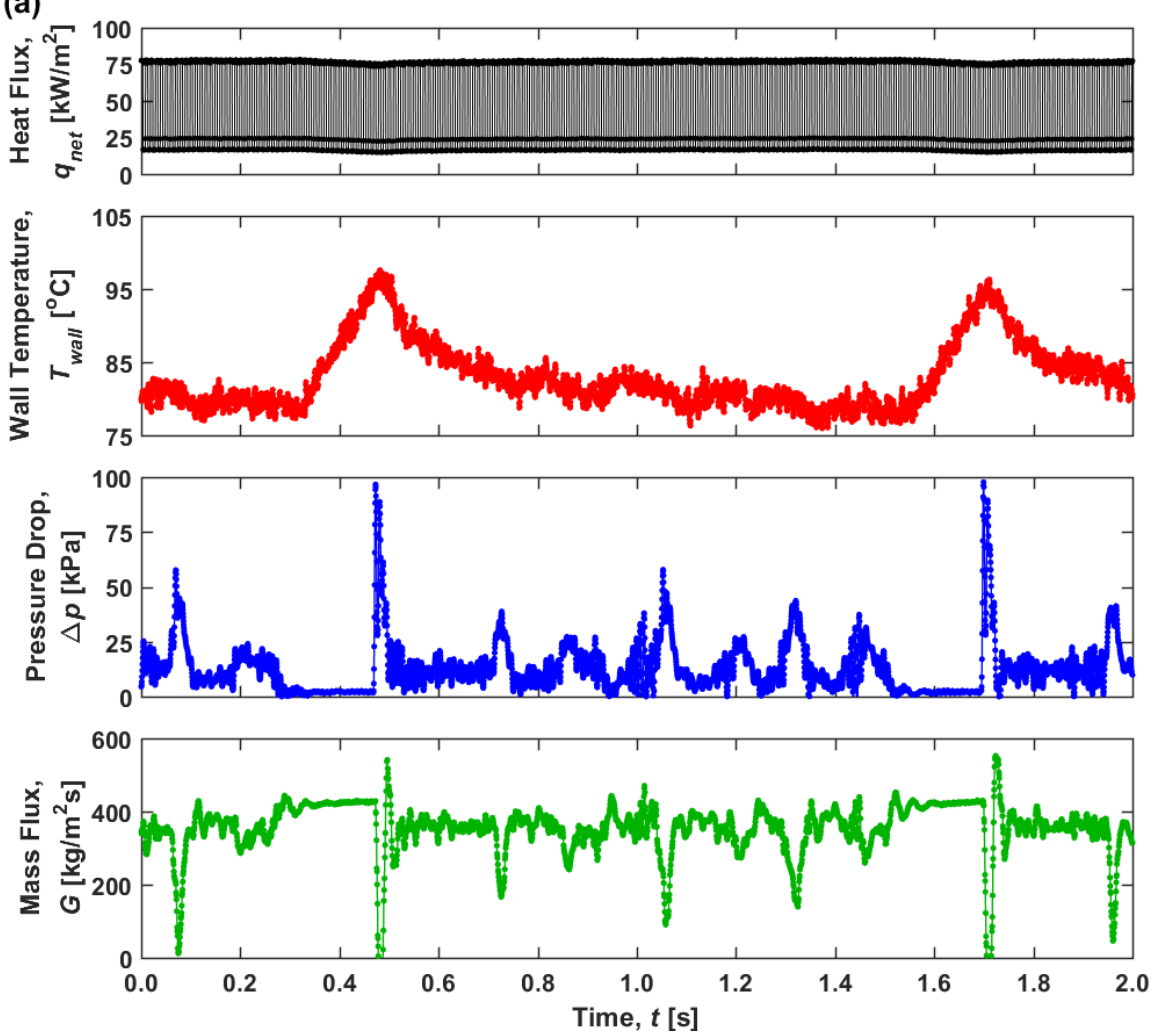

(b) Normalized Spectral Density [-]
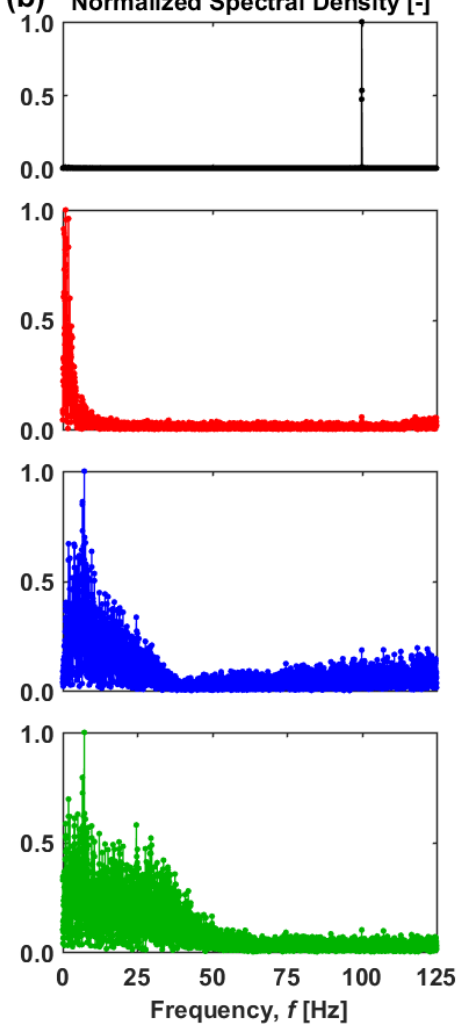

Figure 6. (a) Heat flux, wall temperature, pressure drop, and mass flux as a function of time for heat flux pulses between 15 and $75 \mathrm{~kW} / \mathrm{m}^{2}$ (operating scenario 1) at $100 \mathrm{~Hz}$. A corresponding 
video of the synchronized flow visualizations and sensor measurements is available online in the Supplementary Materials (Video S4). (b) Normalized spectral density of the sensor measurements.

Shown in Figure 7 are the sensor measurements for heat flux pulses between 15 and 150 $\mathrm{kW} / \mathrm{m}^{2}$ at $1 \mathrm{~Hz}$ and the corresponding normalized spectral density of the signals. For operating scenario 2 (i.e., pulses between 15 and $150 \mathrm{~kW} / \mathrm{m}^{2}$ ), the fluid in the microchannel boils continuously regardless of the heating pulse frequency. Spectral analysis of the sensor measurements indicates that heating pulses at $1 \mathrm{~Hz}$ are driving the thermal and hydrodynamic fluctuations at exactly the heating pulse frequency, as shown in Figure 7b. As shown in Figure $7 \mathrm{a}$, during the pulses to $150 \mathrm{~kW} / \mathrm{m}^{2}$, the wall temperature increases continuously, and timeperiodic oscillations in the pressure drop and mass flux are observed. Between pulses, the wall temperature reduces and the pressure drop and mass flux signals flatten out because the vapor in the channel moves downstream. During individual pulses to $150 \mathrm{~kW} / \mathrm{m}^{2}$, high-frequency pressure drop oscillations are occurring at $32 \mathrm{~Hz}$, as shown by the peak in the normalized spectral density of the mass flux signal in Figure $7 \mathrm{~b}$. The large increase in the intrinsic pressure drop oscillation frequency at $150 \mathrm{~kW} / \mathrm{m}^{2}$, relative to those previously observed at lower heat flux levels, is due to vapor nucleating from the microchannel wall near the inlet of the channel. This reduces the length of the channel that vapor travels upstream when undergoing the pressure drop instability and thus increases the intrinsic frequency of the oscillations, as was discussed in Part 1 of this two-part study [13]. 
(a)
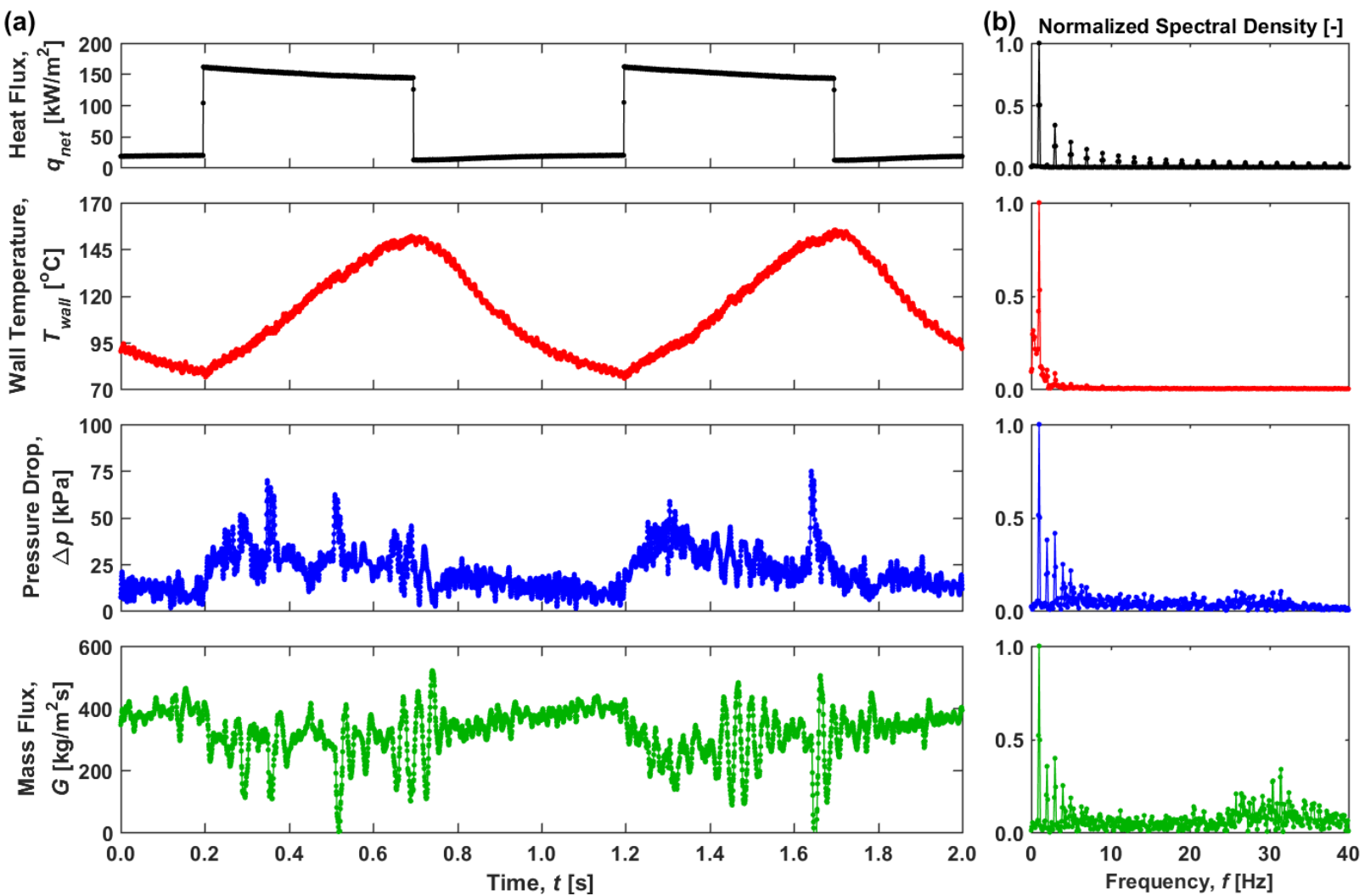

Figure 7. (a) Heat flux, wall temperature, pressure drop, and mass flux as a function of time for heat flux pulses between 15 and $150 \mathrm{~kW} / \mathrm{m}^{2}$ (operating scenario 2) at $1 \mathrm{~Hz}$. A corresponding video of the synchronized flow visualizations and sensor measurements is available online in the Supplementary Materials (Video S5). (b) Normalized spectral density of the sensor measurements.

The obtained sensor measurements for heat flux pulses between 15 and $150 \mathrm{~kW} / \mathrm{m}^{2}$ at 5 $\mathrm{Hz}$ and the corresponding normalized spectral density of the signals are displayed in Figure 8. As in operating scenario 1, a heating pulse frequency of $5 \mathrm{~Hz}$ for operating scenario 2 forces the pressure drop instability to occur exactly at this frequency. Large fluctuations in the wall temperature, pressure drop, and mass flux exactly match the frequency of the heat flux profile, as shown in Figure 8a. These fluctuations are so distinct that a single spike in the normalized spectral density for each sensor measurement is observed in Figure $8 \mathrm{~b}$. 
(a)
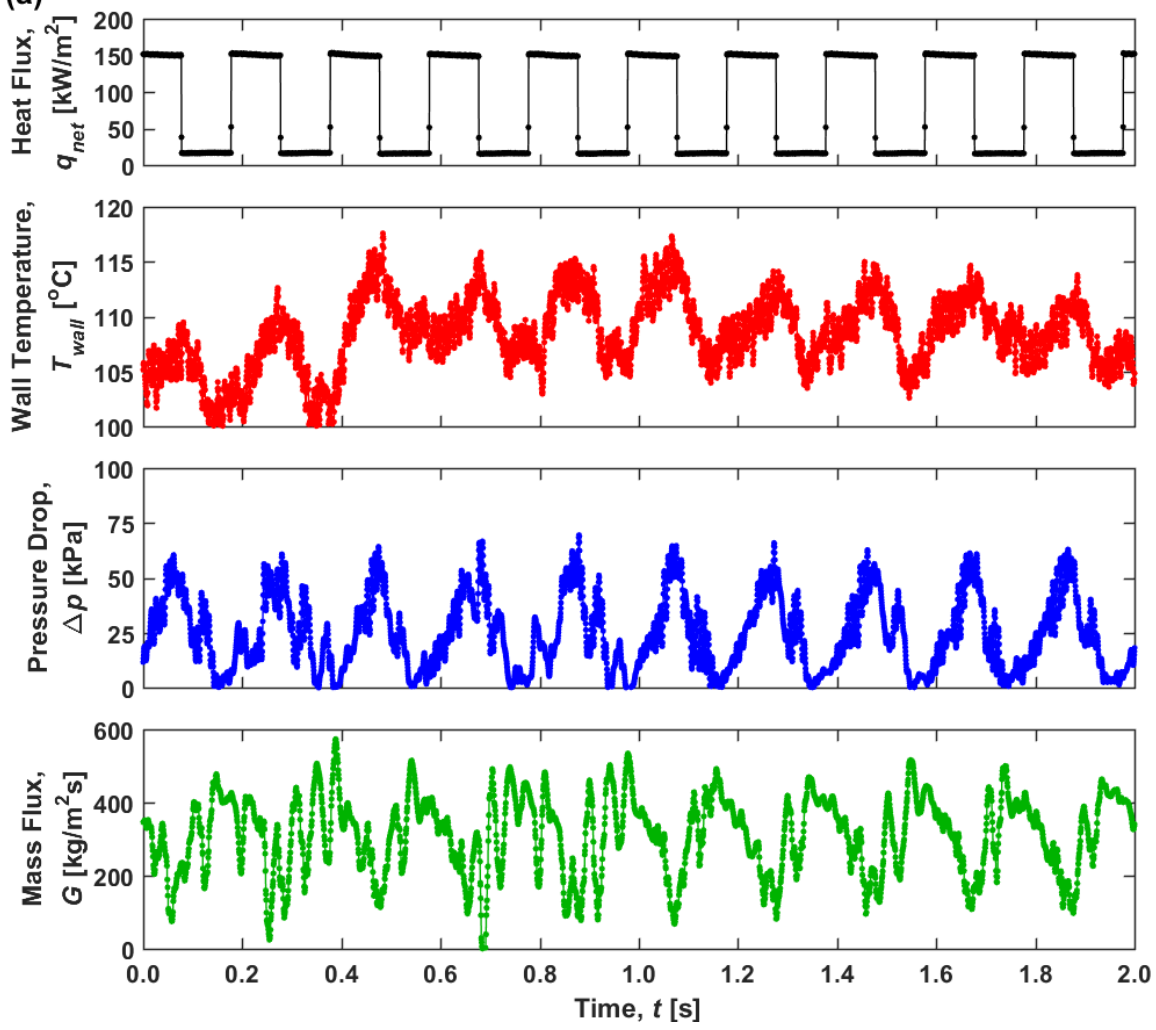

(b) Normalized Spectral Density [-]
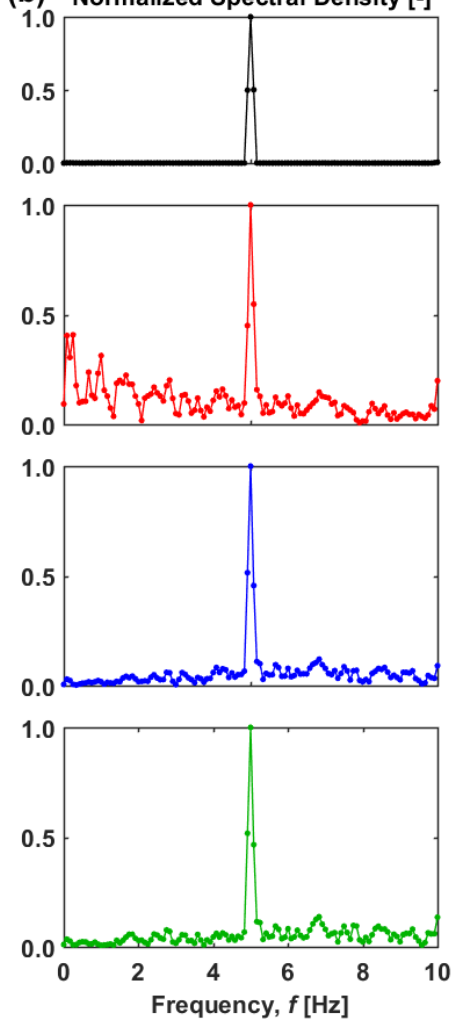

Figure 8. (a) Heat flux, wall temperature, pressure drop, and mass flux as a function of time for heat flux pulses between 15 and $150 \mathrm{~kW} / \mathrm{m}^{2}$ (operating scenario 2) at $5 \mathrm{~Hz}$. A corresponding video of the synchronized flow visualizations and sensor measurements is available online in the Supplementary Materials (Video S6). (b) Normalized spectral density of the sensor measurements.

Shown in Figure 9 are the sensor measurements for heat flux pulses between 15 and 150 $\mathrm{kW} / \mathrm{m}^{2}$ at $10 \mathrm{~Hz}$ and the corresponding normalized spectral density of the signals. The wall temperature, pressure drop, and mass flux fluctuate at $10 \mathrm{~Hz}$, corresponding to the heating pulse frequency. Superimposed on these small amplitude oscillations are much larger amplitude oscillations (most identifiable in the pressure drop and mass flux signal) at $5 \mathrm{~Hz}$, which corresponds to the pressure drop instability, as indicated by the small peak in the normalized spectral density at this frequency in Figure $9 \mathrm{~b}$. This peak is much broader as compared to when 
the heating pulse frequency forces the pressure drop oscillations (e.g., at $5 \mathrm{~Hz}$ in Figure 4 and Figure 8).

(a)
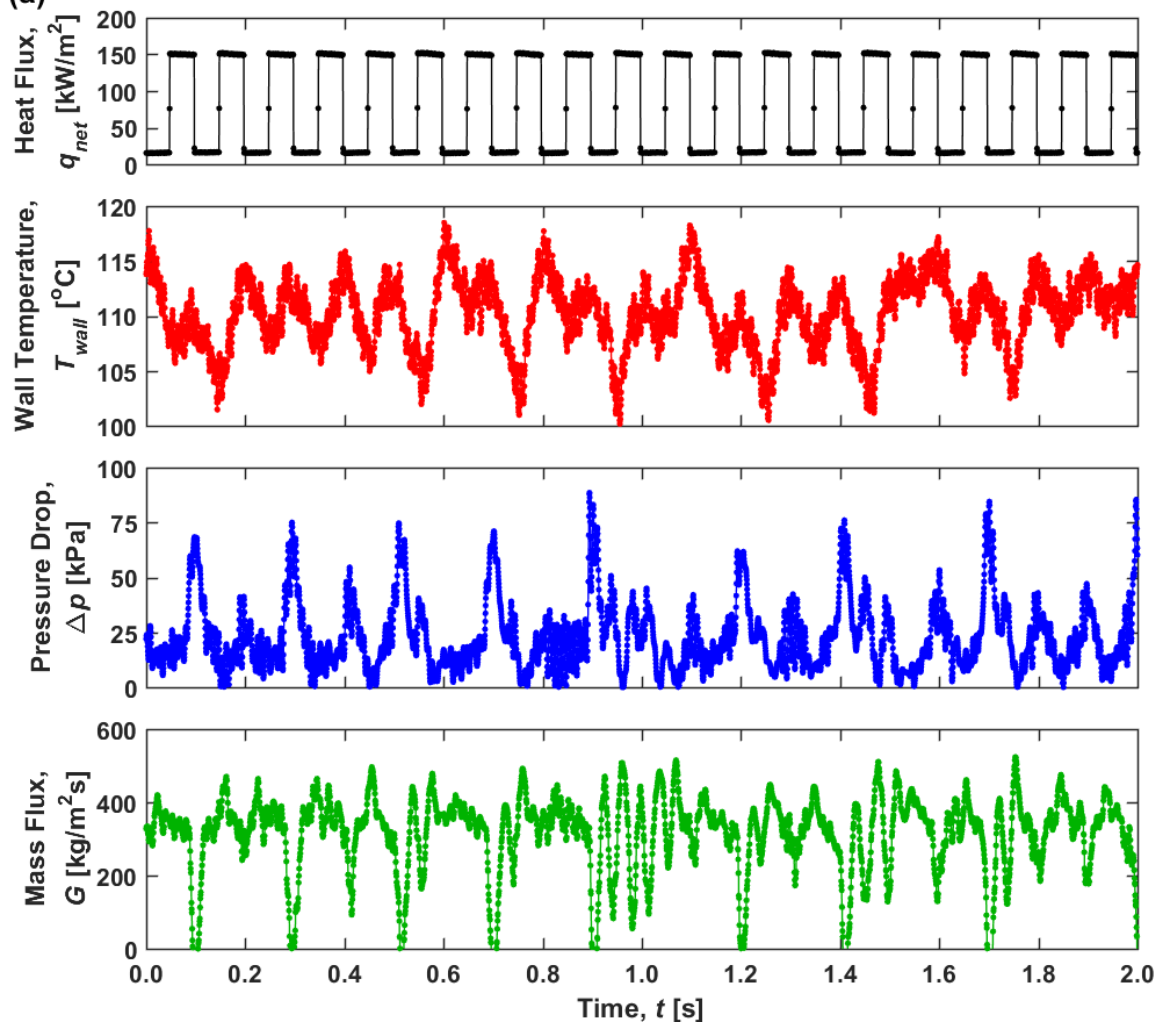
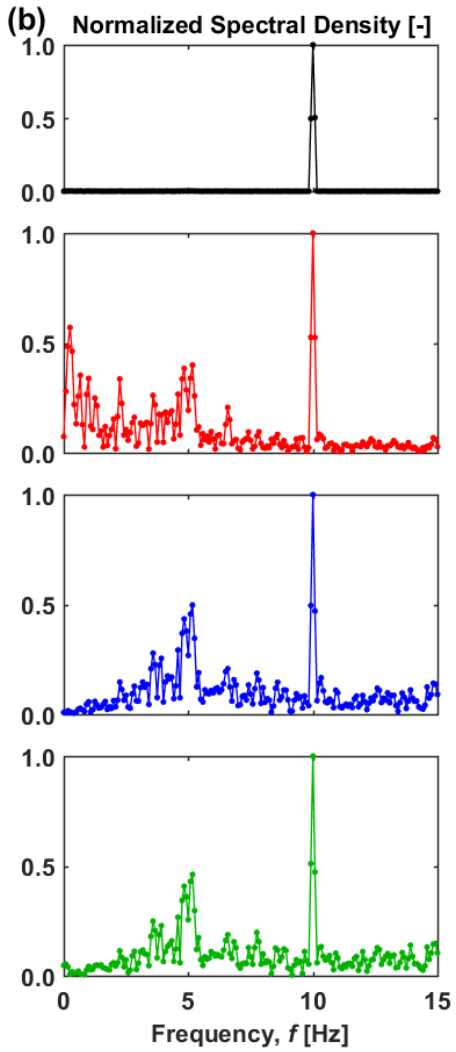

Figure 9. (a) Heat flux, wall temperature, pressure drop, and mass flux as a function of time for heat flux pulses between 15 and $150 \mathrm{~kW} / \mathrm{m}^{2}$ (operating scenario 2) at $10 \mathrm{~Hz}$. A corresponding video of the synchronized flow visualizations and sensor measurements is available online in the Supplementary Materials (Video S7). (b) Normalized spectral density of the sensor measurements.

\subsection{Broader Implications and the Significance of the Transient Heating Timescale}

While the transient response data reported in this study are specific to the experimental conditions and heating profiles investigated, broader conclusions can be drawn by interpreting the results in the context of the thermal time constant of the test section. When the thermal time 
constant of the test section microchannel is on the same order as the timescales of the transient heating events $(e . g$., in the intermediate heating pulse frequency range of $1<f<10 \mathrm{~Hz}$ in this study), the flow boiling instabilities and performance will be strongly coupled to the transient heating conditions. Furthermore, it is noteworthy that heating pulses to very high heat fluxes, which would cause dryout if applied continuously, can be withstood if the timescales of these pulses are shorter than the thermal time constant (e.g., $5 \mathrm{~Hz}$ pulses to $\left.150 \mathrm{~kW} / \mathrm{m}^{2}\right)$. Therefore, to extrapolate these conclusions to other two-phase cooling systems and identify transient heating levels and timescales of concern, it is critical to estimate or characterize the thermal time constant (as described in Section 3.2 in Part 1 of this study [13]). As next-generation cooling strategies seek to miniaturize and closely integrate flow channels into electronic devices and/or packages, reduced thermal time constants will lead to increased coupling between the device operation and cooling performance that must be considered.

\section{Conclusions}

The effects of heating pulse frequency on the resulting time-periodic fluctuations during microchannel flow boiling were experimentally investigated. A time-periodic series of heat flux pulses applied to the microchannel via an ITO coating was varied between 15,75 , and 150 $\mathrm{kW} / \mathrm{m}^{2}$ for heating pulse frequencies ranging from $0.1 \mathrm{~Hz}$ to $100 \mathrm{~Hz}$. These three heat flux levels were selected because they exhibited highly contrasting flow conditions under constant heating conditions, namely single-phase flow, continuous two-phase flow, and a heat flux which exceeds critical heat flux and would cause dryout if applied as a constant input. High-speed optical visualizations of the two-phase morphology were synchronized to high-frequency measurements of the heat flux, wall temperature, pressure drop, and mass flux. Spectral analysis 
was applied to the sensor measurements to determine the characteristic fluctuation frequencies resulting from the transient heating conditions.

Three different time-periodic flow boiling fluctuations were observed: flow regime transitions, pressure drop oscillations, and heating pulse propagation. The range over which these oscillations were observed were then mapped to the heating pulse frequency (Figure 2) and key observations and takeaways were presented (Table 2). In general, it was observed that: (i) low heating frequencies $(f \leq 1 \mathrm{~Hz})$ cause a dynamic response that resembles multiple independent step changes between different heat flux levels that each reach a new steady condition, (ii) at intermediate heating frequencies $(1<f<10 \mathrm{~Hz})$, near the timescale of the thermal time constant of the test section, the flow boiling instabilities and performance are heavily coupled to the heating profile thus causing the pressure drop oscillation frequency to exactly match the heating pulse frequency, and (iii) at high heating frequencies $(f \geq 10 \mathrm{~Hz})$, the transient heat flux profile is attenuated and becomes effectively a constant heat flux above $\sim 25$ Hz. The observed dependence of flow instabilities and thermal performance on time-varying heating conditions indicates that flow boiling dynamics will significantly influence overall performance in various applications.

\section{Acknowledgments}

This research was sponsored by the Naval Engineering Education Consortium (NEEC), with support of Naval Surface Warfare Center (NSWC) Crane Division in Crane, Indiana. Special thanks to Dr. Brian D. Olson (NSWC Crane Division) for technical discussion of this work. 


\section{Appendix A. Supplementary material}

Supplementary material associated with this article can be found in the online version.

\section{References}

[1] J.A. Boure, A.E. Bergles, L.S. Tong, Review of two-phase flow instability, Nuclear Engineering and Design, 25(2) (1973) 165-192.

[2] S. Kakac, B. Bon, A review of two-phase flow dynamic instabilities in tube boiling systems, International Journal of Heat and Mass Transfer, 51(3-4) (2008) 399-433.

[3] L.C. Ruspini, C.P. Marcel, A. Clausse, Two-phase flow instabilities: A review, International Journal of Heat and Mass Transfer, 71 (2014) 521-548.

[4] W. Qu, I. Mudawar, Measurement and prediction of pressure drop in two-phase microchannel heat sinks, International Journal of Heat and Mass Transfer, 46(15) (2003) 27372753.

[5] L.J. Guo, Z.P. Feng, X.J. Chen, Transient convective heat transfer of steam-water twophase flow in a helical tube under pressure drop type oscillations, International Journal of Heat and Mass Transfer, 45(3) (2002) 533-542.

[6] I.W. Park, J. Ryu, M. Fernandino, C.A. Dorao, Can flow oscillations during flow boiling deteriorate the heat transfer coefficient?, Applied Physics Letters, 113(15) (2018).

[7] M. Sorum, C.A. Dorao, Experimental study of the heat transfer coefficient deterioration during density wave oscillations, Chemical Engineering Science, 132 (2015) 194-201.

[8] A.E. Bergles, S.G. Kandlikar, On the nature of critical heat flux in microchannels, Journal of Heat Transfer, 127(1) (2005) 101-107.

[9] M. Ozawa, H. Umekawa, K. Mishima, T. Hibiki, Y. Saito, CHF in oscillatory flow boiling channels, Chemical Engineering Research and Design, 79(A4) (2001) 389-401.

[10] J.L. Miler, R. Flynn, G. Refai-Ahmed, M. Touzelbaev, M. David, J. Steinbrenner, K.E. Goodson, Effects of transient heating on two-phase flow response in microchannel heat exchangers, Proceedings of ASME InterPACK, 2 (2010) 563-569. 
[11] G.M. Aguiar, G. Ribatski, The effect of transient power hotspots on the heat transfer coefficient during flow boiling inside single microscale channels, Heat Transfer Engineering, (2018) 1-12.

[12] H. Huang, N. Borhani, J. Thome, Thermal response of multi-microchannel evaporators during flow boiling of refrigerants under transient heat loads with flow visualization, Journal of Electronic Packaging, 138(3) (2016) 031004.

[13] T.A. Kingston, J.A. Weibel, S.V. Garimella, Time-resolved characterization of microchannel flow boiling during transient heating: Part 1 - Dynamic response to a single heat flux pulse, International Journal of Heat and Mass Transfer (in review).

[14] K.P. Drummond, D. Back, M.D. Sinanis, D.B. Janes, D. Peroulis, J.A. Weibel, S.V. Garimella, A hierarchical manifold microchannel heat sink array for high-heat-flux twophase cooling of electronics, International Journal of Heat and Mass Transfer, 117 (2018) 319-330.

[15] K.P. Drummond, D. Back, M.D. Sinanis, D.B. Janes, D. Peroulis, J.A. Weibel, S.V. Garimella, Characterization of hierarchical manifold microchannel heat sink arrays under simultaneous background and hotspot heating conditions, International Journal of Heat and Mass Transfer, 126 (2018) 1289-1301. 